\title{
New species of Cryptosporidium Tyzzer, 1907 (Apicomplexa) from amphibian host: morphology, biology and phylogeny
}

\author{
Miloslav Jirků ${ }^{1,2}$, Andrea Valigurová ${ }^{3}$, Břetislav Koudela $^{1,2}$, Jaroslav Křížek $^{2}$, David Modrý $^{1,2}$ and \\ Jan Šlapeta ${ }^{4}$ \\ ${ }^{1}$ Department of Parasitology, University of Veterinary and Pharmaceutical Sciences, Palackého 1-3, 61242 Brno, Czech \\ Republic; \\ ${ }^{2}$ Institute of Parasitology, Biology Centre of the Academy of Sciences of the Czech Republic, Branišovská 31, 37005 České \\ Budějovice, Czech Republic; \\ ${ }^{3}$ Department of Botany and Zoology, Faculty of Science, Masaryk University, Kotlářská 2, 61137 Brno, Czech Republic; \\ ${ }^{4}$ Faculty of Veterinary Science, University of Sydney, McMaster Building - B14, New South Wales 2006, Australia
}

Key words: Cryptosporidium fragile, new species, frog, Duttaphrynus melanostictus, ultrastructure, host specificity, phylogeny, quarantine, global amphibian decline

\begin{abstract}
Cryptosporidium fragile sp. n. (Apicomplexa) is described from black-spined toads, Duttaphrynus melanostictus (Schneider) (Amphibia, Anura, Bufonidae) from the Malay Peninsula. The parasitized animals were directly imported from Malaysia and harboured $C$. fragile at the time of arrival. Oocysts were subspherical to elliptical with irregular contour in optical section, measuring $6.2(5.5-7.0) \times 5.5(5.0-6.5) \mu \mathrm{m}$. Oocyst wall was smooth and colourless in light microscopy. The endogenous development of $C$. fragile in the stomach of black-spined toad was analysed in detail using light and electron microscopy. Cryptosporidian developmental stages were confined to the surface of gastric epithelial cells. In transmission experiments, $C$. fragile has not been infective for one fish species, four amphibian species, one species of reptile and SCID mice. Full length small subunit rRNA gene sequence was obtained. Phylogenetic reconstruction revealed distinct status of $C$. fragile within the clade of species with gastric localisation including Cryptosporidium muris Tyzzer, 1907, Cryptosporidium serpentis Levine, 1980 and Cryptosporidium andersoni Lindsay, Upton, Owens, Morgan, Mead et Blagburn, 2000. Described characteristics differentiate $C$. fragile from the currently recognized Cryptosporidium species. Our experience with the description of $C$. fragile has led us to revise the recommended criteria for an introduction of a new Cryptosporidium species name. C. fragile is the first species described and named from an amphibian host. Its prevalence of $83 \%(15 / 18)$ in black-spined toads within the 3 months after importation calls for strict quarantine measures and import regulation for lower vertebrates.
\end{abstract}

The genus Cryptosporidium was erected by Ernest E. Tyzzer for a peculiar parasite affecting mouse stomach, Cryptosporidium muris Tyzzer, 1907 (Tyzzer 1907). Later he recognized a distinct species Cryptosporidium parvum Tyzzer, 1912 affecting mouse intestine (Tyzzer 1912). In the following years, multiple new cryptosporidian species were described, infecting majority of vertebrates. Initially, cryptosporidia were considered of a doubtful clinical significance, but with increasing knowledge the disease, cryptosporidiosis, was recognized as a major concern in immunocompromised and even healthy hosts (Fayer et al. 2000, Chen et al. 2002, Thompson et al. 2005).

Currently, there are 21 recognized species within the genus Cryptosporidium in fish, reptiles, birds and mammals (Šlapeta 2008). Seven of these affect host's stomach - C. muris Tyzzer, 1907 in rodents, C. andersoni Lindsay, Upton, Owens, Morgan, Mead et Blagburn, 2000 in cattle, C. serpentis Levine, 1980 in snakes and lizards, C. galli Pavlásek, 1999 in birds, and three species in fish stomach $-C$. cichlidis (Paperna et Vilenkin, 1996), C. reichenbachklinkei (Paperna et Vilenkin, 1996) and C. molnari Alvarez-Pellitero et SitjàBobadilla, 2002 (Paperna and Vilenkin 1996, Tilley et al. 1990, Lindsay et al. 2000, Alvarez-Pellitero and Sitjà-Bobadilla 2002, Ryan et al. 2003a).

Here we report on a cryptosporidian infection in toads directly imported to the Czech Republic from Malaysia for pet trade. We summarise morphological characteristics, results of transmission experiments and molecular data to describe this isolate as a new Cryptosporidium species, representing the first characterized species from an amphibian host.

\section{MATERIALS AND METHODS}

Origin of the parasites and host animals. In total, 18 adult black-spined toads, Duttaphrynus (syn. Bufo) melanostictus (Schneider) (Amphibia, Bufonidae) were obtained via import of pet animals from the Malay Peninsula in April 2006 $(\mathrm{n}=9)$ and May $2006(\mathrm{n}=9)$ in accordance with the Czech Republic regulations. Toads arrived in plastic boxes with moist moss, 3-4 individuals per box, and were quarantined in the premises of the University of Veterinary and Pharmaceutical Sciences Brno, Czech Republic (UVPB). The animals were housed individually in 8-litre glass vivaria with wet coco substrate, and fed 2-3 times weekly with crickets (Gryllus assimilis) supplemented with Reptivite (ZooMed Laboratories Inc). 
Parasitological examination. All faeces expelled by individual toads were monitored for the presence of parasites using flotation (sugar solution, s.g. 1.3) from the day of import up to 90 days after arrival. Animals shedding oocysts were euthanised by pithing. Fresh squash preparations of various viscera, gastrointestinal smears, histological preparations and oocysts concentrated by flotation were examined by light microscopy using an Olympus AX 70 microscope equipped with Nomarski interference-contrast optics (NIC). For histology, the tissues of three animals were fixed in $10 \%$ buffered formalin or AFA (Alcohol-Formalin-Acetic Acid), embedded in Histoplast II and $6 \mu \mathrm{m}$ sections were stained with haematoxylin-eosin (H\&E). For transmission electron microscopy (TEM), the tissues of two animals were fixed overnight at $4{ }^{\circ} \mathrm{C}$ in 3\% glutaraldehyde in $0.2 \mathrm{M}$ phosphate buffer and processed as described previously (Valigurová et al. 2008). Ultrathin sections were double-stained with uranyl acetate and lead citrate and viewed in a JEOL 1010. For scanning electron microscopy (SEM), the tissues of three animals were fixed overnight at $4{ }^{\circ} \mathrm{C}$ in $3 \%$ glutaraldehyde in cacodylate buffer and processed according to Valigurová et al. (2008). Samples were examined using a JEOL JSM-7401F, field emission scanning electron microscope capable of high resolution of up to $1.0 \mathrm{~nm}$.

Experimental host transmissions. Sieved faecal samples containing Cryptosporidium oocysts were pooled and kept in dechlorinated tap water in 0.5-litre containers without preservatives to avoid intoxication of experimental animals. Every two days, the suspension was stirred, sedimented $(1 \mathrm{~h})$, water removed and the tanks were re-filled with fresh water. The sedimented debris containing oocysts ( $<7$ days old) was used for experimental inoculations. Before each trial, the presence of morphologically intact oocysts in infectious material was confirmed using flotation and oocysts quantification in the Bürker's chamber. Animal work has been approved by the Animal Ethics Committee, UVPB. Experimental animals were inoculated orally, except tadpoles and fish fed (after one day starvation) with a mixture of granulated fish food and the sedimented debris containing oocysts (see Table 1). Experimental animals were kept in separate facility at $20-23^{\circ} \mathrm{C}$ and artificial 12/12 h day/night cycle (UVPB). All faeces were daily collected from experimental enclosures and examined by flotation up to 8 weeks post inoculation (p.i.). After 8 weeks p.i., randomly selected animals (15/20 Poecilia reticulata, $2 / 2$ adult Bufo bufo, 20/40 B. bufo tadpoles, 2/2 adult Rana temporaria, 2/2 adult Litoria caerulea, 5/5 adult Xenopus laevis, $15 / 20 X$. laevis tadpoles, 1/1 Pantherophis guttatus and 2/2 SCID mice) were examined histologically.

Molecular characterisation and phylogenetic analysis. Mashed scraping of stomach mucosa containing microscopically confirmed cryptosporidia was used for the DNA isolation. Preparation in $200 \mu \mathrm{l}$ normal saline solution was extracted using DNA Mini Kit (Qiagen). DNA was eluted in 100 $\mu 1$ of distilled water and stored at $-20^{\circ} \mathrm{C}$.

The full-length small subunit rRNA gene (SSU rDNA) was amplified using 5'-AAC CTG GTT GAT CCT GCC AGT AGT C and 5'-TGA TCC TTC TGC AGG TTC ACC TAC G primers (Xiao et al. 1999). PCR conditions consisted of 35 cycles of denaturation at $94^{\circ} \mathrm{C}$ for $60 \mathrm{~s}$, annealing at $55^{\circ} \mathrm{C}$ for $60 \mathrm{~s}$, and extension at $72^{\circ} \mathrm{C}$ for $120 \mathrm{~s}$; including an initial denaturation at $94^{\circ} \mathrm{C}$ for $5 \mathrm{~min}$ and a final extension at $72^{\circ} \mathrm{C}$ for $10 \mathrm{~min}$. PCRs were carried out in $50 \mu \mathrm{l}$, containing $5 \mu \mathrm{l}$ of DNA eluate, 100 pmoles of each primer, $1 \mathrm{U}$ of Taq DNA polymerase in PCR buffer (TaKaRa). Negative and positive controls were included in all PCR runs. PCR reaction was electrophoresed and visualised with ethidium bromide. Amplicons were cloned into pCR2.1 vector according to manufacturer's instructions (TA TOPO Cloning Kit, Invitrogen). Full inserts were bidirectionally sequenced (Biotech, Germany) from 6 random clones. The SSU rDNA are available in the GenBank $^{\mathrm{TM}}$ under the accession numbers EU162751EU162754.

Nucleotide sequences were searched (blastn) against a local database of available Cryptosporidium spp. sequences, comprising 622 SSU rDNAs from GenBank ${ }^{\mathrm{TM}}$ (as of 28/8/2007). New sequences were manually added to the curated alignment of sequences comprising named species, major genotypes and the nearest neighbours (available upon request from authors). The alignments were analysed using a maximum likelihood (ML) phylogenetic approach PhyML 2.4.4 (Guindon and Gascuel 2003) that requires a model of nucleotide evolution selected using standard AIC in ModelTest 3.6 (Posada and Crandall 1998). Maximum parsimony (MP) and Minimum evolution (ME) were calculated in MEGA4 (Tamura et al. 2007).

Table 1. Experimental host transmissions of Cryptosporidium fragile sp. $\mathrm{n}$.

\begin{tabular}{|c|c|c|c|c|c|}
\hline Experimental host & $\begin{array}{l}\text { Host stage } \\
\text { (age) }\end{array}$ & $\begin{array}{l}\text { No. infected } \\
\text { (control) }\end{array}$ & $\begin{array}{l}\begin{array}{l}\text { Dose } \\
\text { (oocysts) }\end{array} \\
\end{array}$ & Result & Host origin \\
\hline $\begin{array}{c}\text { FISH } \\
\text { Poecilia reticulate }\end{array}$ & Adults ( $>1$ year) & $20(10)$ & $10^{3}-10^{4}$ & Neg. & $\mathrm{PC}$ \\
\hline $\begin{array}{l}\text { AMPHIBIANS } \\
\text { Bufo bufo }\end{array}$ & $\begin{array}{l}\text { Adults ( }>3 \text { years) } \\
\text { Tadpoles }\end{array}$ & $\begin{array}{l}2(2) \\
40(40)\end{array}$ & $\begin{array}{l}10^{4} \\
\text { unknown }\end{array}$ & $\begin{array}{l}\text { Neg. } \\
\text { Neg. }\end{array}$ & $\begin{array}{l}\mathrm{W} \\
\mathrm{W}\end{array}$ \\
\hline Rana temporaria & Adults ( $>3$ years) & $2(2)$ & $10^{4}$ & Neg. & $\mathrm{W}$ \\
\hline Litoria caerulea & Adults $(>3$ years $)$ & $2(1)$ & $10^{4}$ & Neg. & PI \\
\hline Xenopus laevis & Adults ( $>2$ years) & $5(5)$ & $10^{4}$ & Neg. & LC \\
\hline & Tadpoles & $20(20)$ & unknown & Neg. & LC \\
\hline $\begin{array}{c}\text { REPTILES } \\
\text { Pantherophis guttatus }\end{array}$ & Adult (2 years) & $1(1)$ & $10^{4}$ & Neg. & $\mathrm{PC}$ \\
\hline $\begin{array}{c}\text { MAMMALS } \\
\text { Mus musculus SCID }\end{array}$ & Subadults (12 weeks) & $2(2)$ & $10^{4}$ & Neg. & LC \\
\hline
\end{tabular}

LC - laboratory colony (Xenopus laevis from the University of Veterinary and Pharmaceutical Sciences Brno and SCID mice from the Charles Rivers Laboratories); PC - pet trade, captive-bred; PI - pet trade, import from the wild; W - wild-caught in Brno, Czech Republic. 


\section{RESULTS}

Parasitological examination of black-spined toads, Duttaphrynus melanostictus (Fig. 1) from the Malay Peninsula, revealed that $83 \%(15 / 18)$ passed oocysts of Cryptosporidium. Morphological, experimental and molecular analyses showed that the isolate represents a new species, the description of which follows.

\section{Cryptosporidium fragile sp. $\mathrm{n}$.}

Figs. 2-35

Oocyst morphology. Oocysts (Figs. 2, 3, 6) obtained by flotation method (Fig. 2) from fresh faeces were irregular in shape, subspherical to elliptical; usually with apparently deformed/uneven contour in optical section; $6.2(5.5-7.0) \times 5.5(5.0-6.5) \mu \mathrm{m} ;$ length/width 1.13 $(1.00-1.30)(n=50)$; oocyst wall smooth, colourless in light microscopy. To confirm that the oocyst shape variability is not an artefact, oocysts were examined in native preparations from freshly euthanised animals. Oo- cysts observed in squash preparations of gastric mucosa (Fig. 3) showed the same degree of the shape variability; $6.5(6.0-7.5) \times 5.8(5.0-6.5) \mu \mathrm{m}$; length/width 1.13 $(1.00-1.36)(\mathrm{n}=50)$. Oocyst residuum was composed of a mass of fine granules $0.5 \mu \mathrm{m}$ in diameter, and a spherical globule $1.5-2.0 \mu \mathrm{m}$ in diameter. A large vacuolated area occupied a significant part of the oocyst residuum in all oocysts. Sporulation was endogenous; oocysts were fully sporulated in fresh faeces and gut content. Four vermiform sporozoites lay parallel along one side of oocyst, tightly enclosing oocyst residuum. Neither nucleus nor refractile bodies were observed within sporozoites using light microscopy. Noteworthy, oocysts were extremely sensitive to hypertonic conditions, crumpling immediately when exposed to flotation solutions. The fragility of oocysts was further confirmed by SEM examination of oocysts concentrated by flotation (not shown). Oocysts spontaneously disintegrated after 4 weeks of storage in water at $4^{\circ} \mathrm{C}, 10^{\circ} \mathrm{C}$ and $20^{\circ} \mathrm{C}$.
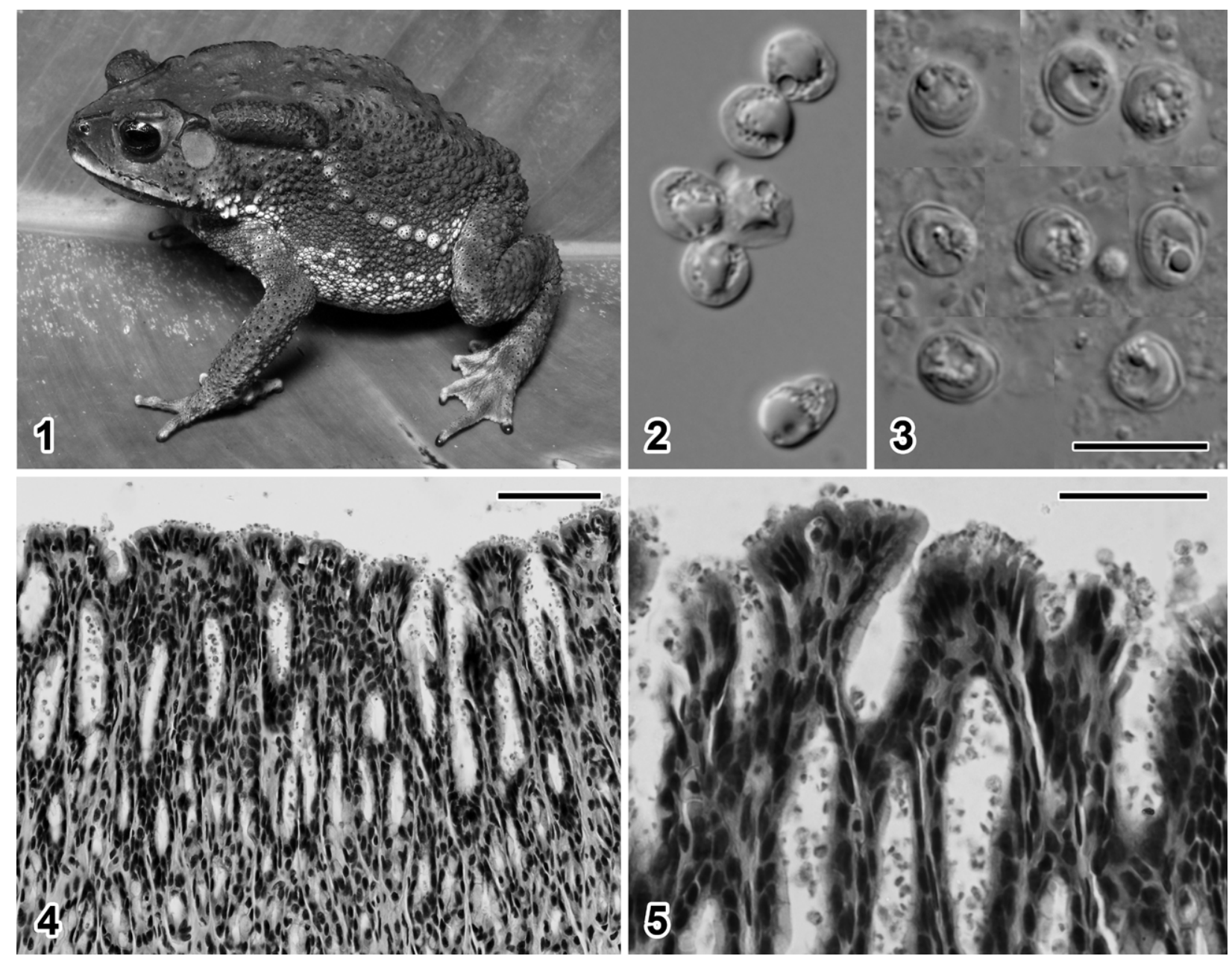

Figs. 1-5. Type host and light microscopy of Cryptosporidium fragile sp. n. Fig. 1. Black-spined toad, Duttaphrynus melanostictus, the type host. Specimen from the Malay Peninsula, snout-vent length $73 \mathrm{~mm}$. Fig. 2. Oocysts from faeces, flotation (NIC). Fig. 3. Composite micrograph of oocysts in squash preparation of the gastric mucosa (NIC). Figs. 4, 5. Stomach of infected toad in longitudinal histological sections (H\&E). Scale bars: Figs. 2, 3 (same scale) $=10 \mu \mathrm{m}$; Fig. $4=100 \mu \mathrm{m}$; Fig. $5=50 \mu \mathrm{m}$. 


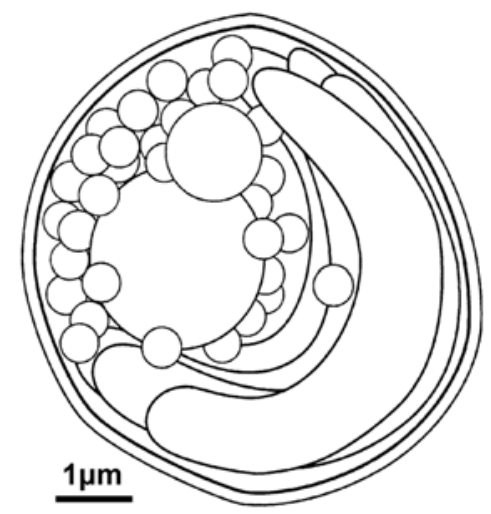

Fig. 6. Composite line drawing of the oocyst of Cryptosporidium fragile sp. n. showing features recognizable using light microscopy. Oocyst wall is shown in optical section.

Prevalence and patent period. Out of 18 toads examined, four $(22 \%)$ passed oocysts at the time of importation. Subsequently, another 11 out of 14 remaining toads started to shed oocysts 6-35 days after arrival. A single oocyst-shedding event was recorded in two animals ( 24 and 35 days after arrival). The rest of the animals shed oocysts for 22-46 days, however the oocyst shedding was mostly intermittent with 7-25 days long recess periods with negative coprological results. Continuous oocyst shedding without recesses was observed in a single animal and lasted for 31 days. In total, 15 $(83 \%)$ toads shed oocysts and three toads $(17 \%)$ remained negative for cryptosporidia during the 90 days of the study. The infections spontaneously disappeared 24-51 days after arrival as indicated by negative coprological results of individual animals and negative results of histology in two animals one week after last oocyst shedding event.

Pathology. At arrival, the toads showed signs of weight loss, weakness and/or apathy that subsided together with eventual spontaneous disappearance of infection in all individual toads. Histopathological examination of the affected gastric tissues showed mild mucosal thickening (Figs. 4, 5) with no further signs of acute or chronic gastritis.

The mucosal surface of the stomach, examined by SEM, revealed severe infection in animals shedding oocysts and unmasked additional pathology. Stomach of C. fragile-affected toads exhibited an irregular surface with foci of swollen cells protruding into the lumen (Figs. 9, 10), contrasting with the smooth surface of the stomach mucosa of uninfected animals (Figs. 7, 8). Swollen cells, not directly parasitized by $C$. fragile, had rounded appearance, and were bulbously protuberant with less distinct intercellular borders when compared with unaffected stomach (compare Figs. 7, 8 and 9-12).

Site of infection. Histological examination of gastrointestinal tract of toads shedding $C$. fragile oocysts revealed the presence of cryptosporidian developmental stages confined to the surface of gastric epithelial cells (Figs. 4, 5). No developmental stages were found in other examined tissues. The parasites were located within parasitophorous sac(s) at the microvillous surface of the epithelium, evenly distributed throughout both the luminal surface of gastric epithelium and the crypts of gastric glands (Figs. 4, 5, 9-13).

Endogenous development and ultrastructure. All developmental stages, except for invading zoites and early trophozoites, were observed in TEM and exhibited typical apicomplexan ultrastructural characteristics (e.g. three-layered pellicle; zoites with apical complexes). Trophozoites and successive stages were enveloped by the parasitophorous sac (Figs. 10-14) possessing distinct radial folds on outer surface of its base (Figs. 17, 22). Typical multilayered dense band was present within affected host cell, separating its unmodified part from the rest modified by the parasitophorous sac formation (Fig. 14). The most distinct layer of dense band was apparently indented (Fig. 21). The feeder organelle consisted of numerous longitudinally oriented fine membranous lamellae (Figs. 14, 19). The top of the feeder organelle was separated from filamentous projection by a seemingly two-layered dense line (Fig. 16). Trophozoites variable in shape, contained nucleus with a prominent nucleolus (Figs. 13, 14). Meronts possessed a large residual body and merozoites, which were short and plump while budding (Fig. 14). The anterior region of merozoites was occupied by rhoptries and numerous micronemes (Fig. 15). Macrogamonts, the most commonly observed developmental stages, filling almost the entire space of parasitophorous sac, possessed a large nucleus with a prominent single nucleolus, several dense bodies and amylopectin granules (Fig. 16). Microgamonts possessed a large residual body surrounded by bullet-like microgametes with a flattened anterior end and elongate compact nucleus (Figs. 17, 18). Microgametes lacked flagella. Mature oocysts showed a large oocyst residuum composed of numerous amylopectin granules and few, relatively large, lipid vacuoles. Four curved sporozoites containing a large nucleus and distinct micronemes lay on one side of each oocyst (Figs. 19, 20). Papular structures were present on the inner surface of oocyst wall (Fig. 19). Various developmental stages, still enclosed within parasitophorous sac, were often found detached from the epithelial surface (Fig. 19).

In SEM, free zoites were occasionally observed on the gastric luminal surface (Fig. 23). The youngest observed stages were invading zoites partly enveloped by rising membrane protrusions of the host cell. After formation of parasitophorous sac, bell-shaped trophozoites developed (Fig. 24) and these became rounded (Fig. 25), eventually growing into mature stages (Fig. 26). Young undifferentiated trophozoites were often surrounded by elongated microvilli, which sometimes secondarily (probably due to processing) adhered to the 

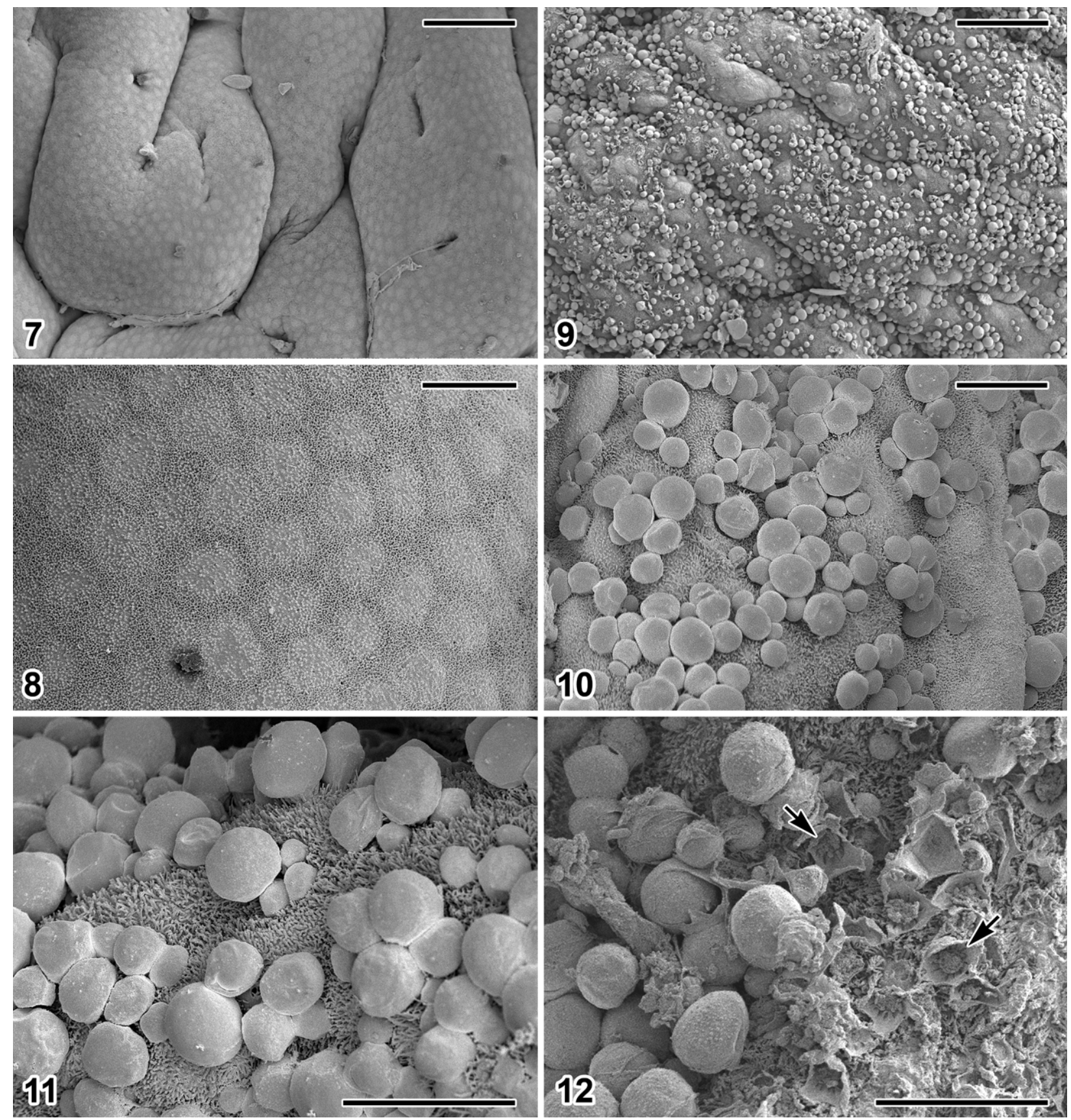

Figs. 7-12. Comparison between gastric epithelium of non-infected and infected toad of Duttaphrynus melanostictus. Figs. 7, 8. Surface of gastric epithelium of non-infected toad. Figs. 9, 10. Surface of infected gastric epithelium covered by numerous developmental stages of Cryptosporidium fragile sp. n. Fig. 11. Surface of gastric epithelium during acute cryptosporidiosis. Fig 12. Surface of gastric epithelium during post-acute cryptosporidiosis. Note the presence of numerous ruptured parasitophorous sacs (arrows). Scale bars: Figs. 7, $9=50 \mu \mathrm{m}$; Figs. 8, 10-12 $=10 \mu \mathrm{m}$.

outer surface of parasitophorous sac (Fig. 24). Mature trophozoites and successive stages were completely enveloped by the parasitophorous sac with distinct, structurally uniform, radial folds that were evenly distributed around its base (Figs. 26-28). Some of completely enveloped parasites were located on a long stem of the host cell origin, the surface of which sometimes possessed microvilli (Figs. 27, 28). Meronts produced merozoites, which were short and plump while budding (Fig. 29) and more elongate and slender when fully matured (Fig. 30). Maturing oocysts were enveloped by parasitophorous sac and showed marked superficial ornamentation (Fig. 31) and a typical semicircular longitudinal suture in the oocyst wall (Fig. 32). Numerous 

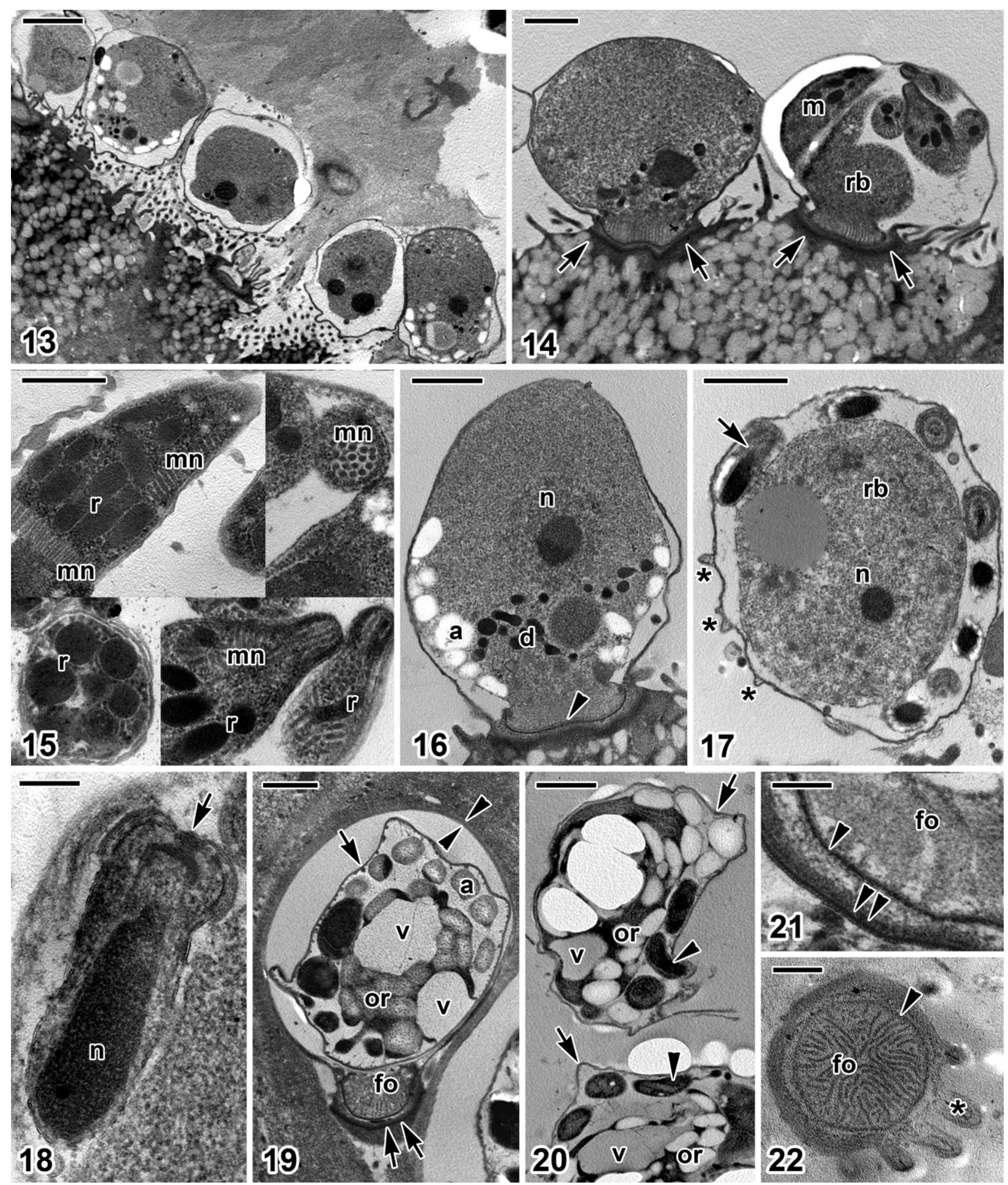

Figs. 13-22. Transmission electron micrographs of Cryptosporidium fragile sp. n. Fig. 13. Gastric epithelium covered by trophozoites and macrogamonts. Fig. 14. Immature macrogamont and meront. Note the distinct dense bands (arrows). Fig. 15. Internal details of merozoites, composite figure. Fig. 16. Macrogamont; dense line (arrowhead). Fig. 17. Microgamont with microgametes (arrow). Fig. 18. Microgamete; apical adhesive zone (arrow). Fig. 19. Oocyst within detached parasitophorous sac; oocyst wall and papular structures on its inner surface (arrow); parasitophorous sac (arrowheads); dense band area (double arrow). Fig. 20. Released oocysts in gastric lumen; sporozoites (arrowheads) with distinct micronemes; oocyst wall (arrows). Fig. 21. Detail of host-parasite interface; dense line (arrowhead); dense band (double arrowhead). Fig. 22. Feeder organelle in cross-section; dense line (arrowhead). Abbreviations: a - amylopectin granules; $\mathrm{d}$ - dense bodies; fo - feeder organelle; $\mathrm{m}$ - merozoite; $\mathrm{mn}$ - micronemes; $\mathrm{n}$ - nucleus; or - oocyst residuum; $\mathrm{r}$ - rhoptries; $\mathrm{rb}$ - residual body; $\mathrm{v}$ - vacuole; * - radial folds of parasitophorous sac. Scale bars: Figs. 13, $19=2 \mu \mathrm{m}$; Figs. 14, 16, 17, $20=1 \mu \mathrm{m}$; Figs. 15, $22=500 \mathrm{~nm}$; Fig. $18=200 \mathrm{~nm}$; Fig. $21=250 \mathrm{~nm}$. 
developmental stages were found detached from the epithelial surface (Fig. 33), showing the base of parasitophorous sac with distinct radial folds inserted under the button-like area of dense band (Figs. 27, 28, 33). Ruptured, empty parasitophorous sacs were often present on the epithelial surface, revealing their bases with the feeder organelles encircled by $\mathrm{Y}$-shaped membrane junctions (annular rings) (Figs. 34, 35).

Experimental host transmissions. None of the experimental animals showed clinical signs of infection and no oocysts were passed in their faeces up to 8 weeks p.i. (Table 1). No endogenous stages were seen during the histological and fresh examinations of gastrointestinal tissue samples from animals killed 8 weeks p.i.

Molecular characterisation and phylogenetic analysis. We sequenced a complete $C$. fragile SSU rDNA sequences. Four obtained sequences, each 1,748 bp long, differed from each other at 7 single nucleotide positions $(4 \times A>G, 2 \times T>C, 1 \times G>A)$. Pairwise distance with available sequences in GenBank ${ }^{\mathrm{TM}}$ revealed that the intestinal C. parvum group of sequences was $90 \%$ identical while the pairwise distance with the gastric $C$. muris / C. andersoni group of sequences was 93\%. Amplification of the protein-coding genes using published primers for COWP and actin (Spano et al. 1997, Xiao et al. 2000, Sulaiman et al. 2002) repeatedly failed to produce a cryptosporidian amplicon.

Phylogenetic reconstruction (Fig. 36) revealed the affinity of $C$. fragile with the gastric clade including $C$. muris, C. andersoni, C. serpentis and C. galli. Sequence of C. galli and genotypes from star tortoise Geochelone elegans, leopard gecko Eublepharis macularius and Eurasian woodcock Scolopax rusticola belong to the gastric clade but have less than $50 \%$ sequence coverage of the full length SSU rDNA and were excluded from the analysis where only complete sequences were included (Fig. 36, inset). ME and MP phylogenetic reconstruction revealed monophyly of the gastric clade. ML did not support the monophyly of gastric sequences, lining them up at the base of the intestinal species. Sequences of $C$. fragile formed a distinct clade within the gastric genotypes and named species. The basal position of $C$. fragile in the gastric clade was supported by low bootstrap support.

\section{DISCUSSION}

The species identification of apicomplexan parasites is traditionally based on the host specificity, the site of infection, and the morphology of life-cycle stages including oocysts. In an attempt to better characterize and describe $C$. fragile we have re-evaluated the current practice for naming new Cryptosporidium species.

\section{The criteria for naming a new species in the genus Cryptosporidium}

Naming a new species is nomenclatural act that is covered by certain rules and practices. In case of the majority of parasitic protozoa including Cryptosporidium spp., it is the International Code of Zoological Nomenclature (ICZN). The stability and longevity of a taxon stands on its holotype, the name bearing specimen used for its description. The type is the specimen(s) illustrated/photographed or described (Article 72.5.6). On the other hand, the fact that the specimen illustrated no longer exists, or cannot be traced, does not invalidate the type designation (Article 73.1.4). The lack of reference material coupled with lack of recognizable morphological differences among named Cryptosporidium spp. have been a major drawback in resolving some of the nomenclatural issues. A consensus on what are the minimal criteria for description of a new species of Cryptosporidium has been previously summarised into four recommended requirements: (i) morphometric studies of oocysts; (ii) genetic characterisations; (iii) demonstration of natural and, whenever feasible, at least some experimental host specificity; and (iv) compliance with ICZN (Egyed et al. 2003, Xiao et al. 2004a).

While we agree, that the oocyst morphology is important, it must not be the only morphological trait investigated for a new species designation. Demonstration of development within the host and ultrastructural analyses should be mandatory information in all descriptive works. While describing $C$. fragile we employed an array of ultrastructural techniques, to better characterize this new species. Besides morphology, the biological characteristics play an essential role in establishing a new species. Localisation, host specificity and pathology associated with an individual host will remain to play a vital role in the species identification. After justifying the mandatory morphological and biological description, an attempt to characterize the isolate genetically at least on a single molecular marker should be made. If such an attempt is considered, complete gene sequences are preferable or even mandatory. Finally yet importantly, it is the differential diagnosis where authors must include the statement how to distinguish the organism from already named species. Singly genetic distinction from already known species should not merit value of differential diagnosis in the species description.

Our experience with the description of $C$. fragile has led us to review and revise the recommended criteria for an introduction of a new Cryptosporidium species name. We summarise the recommended criteria as follows, in compliance with the ICZN. A robust description of (i) morphology of exogenous stages (oocysts) and the morphological demonstration of the developmental stages, accompanied by a deposition of preserved infected tissues for further morphological analyses and (ii) biological characterisation. These should lead to (iii) a differential diagnosis that should, if possible, be supported by (iv) genetic characterisation accompanied by a deposition of sequences and material for further DNA characterisation. Deposited material should be made available 

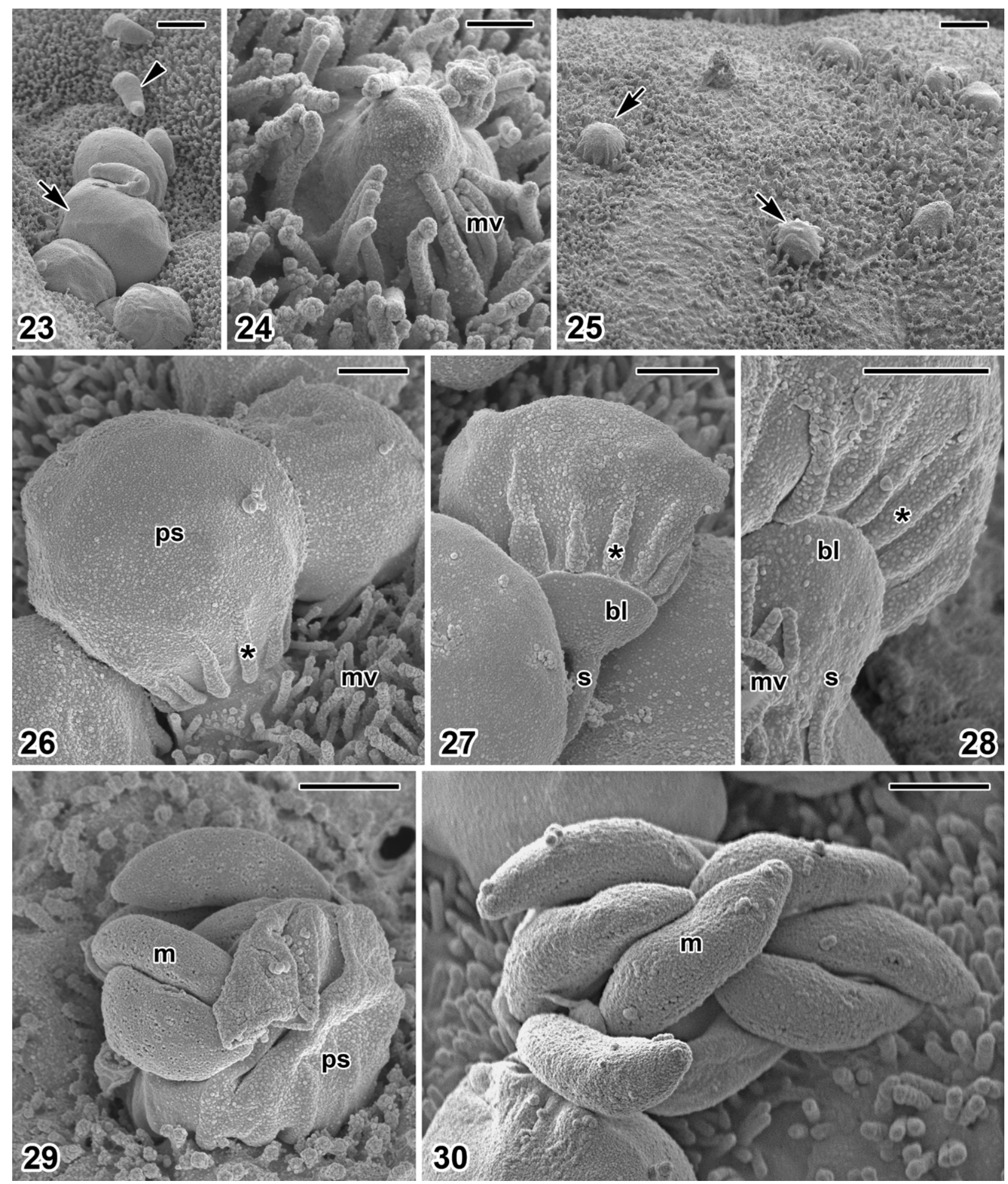

Figs. 23-30. Scanning electron micrographs of Cryptosporidium fragile sp. n. Fig. 23. Unidentified developmental stages (arrow) and released motile zoites (arrowhead). Fig. 24. Young, bell-shaped trophozoite. Fig. 25. Surface of gastric epithelium with several rounded trophozoites (arrows). Fig. 26. Unidentified developmental stages. Figs. 27, 28. Developmental stages with stems. Fig. 29. Immature meront with budding merozoites and ruptured parasitophorous sac. Fig. 30. Mature meront with slender merozoites. Abbreviations: bl - button-like dense band area; $\mathrm{m}$ - merozoite; $\mathrm{mv}$ - microvilli; $\mathrm{ps}$ - parasitophorous sac; $\mathrm{s}-\mathrm{stem}$; $*_{-}$radial folds of parasitophorous sac. Scale bars: Figs. 23, $25=2 \mu$ m; Fig. $24=500 \mathrm{~nm}$; Figs. $26-30=1 \mu \mathrm{m}$. 

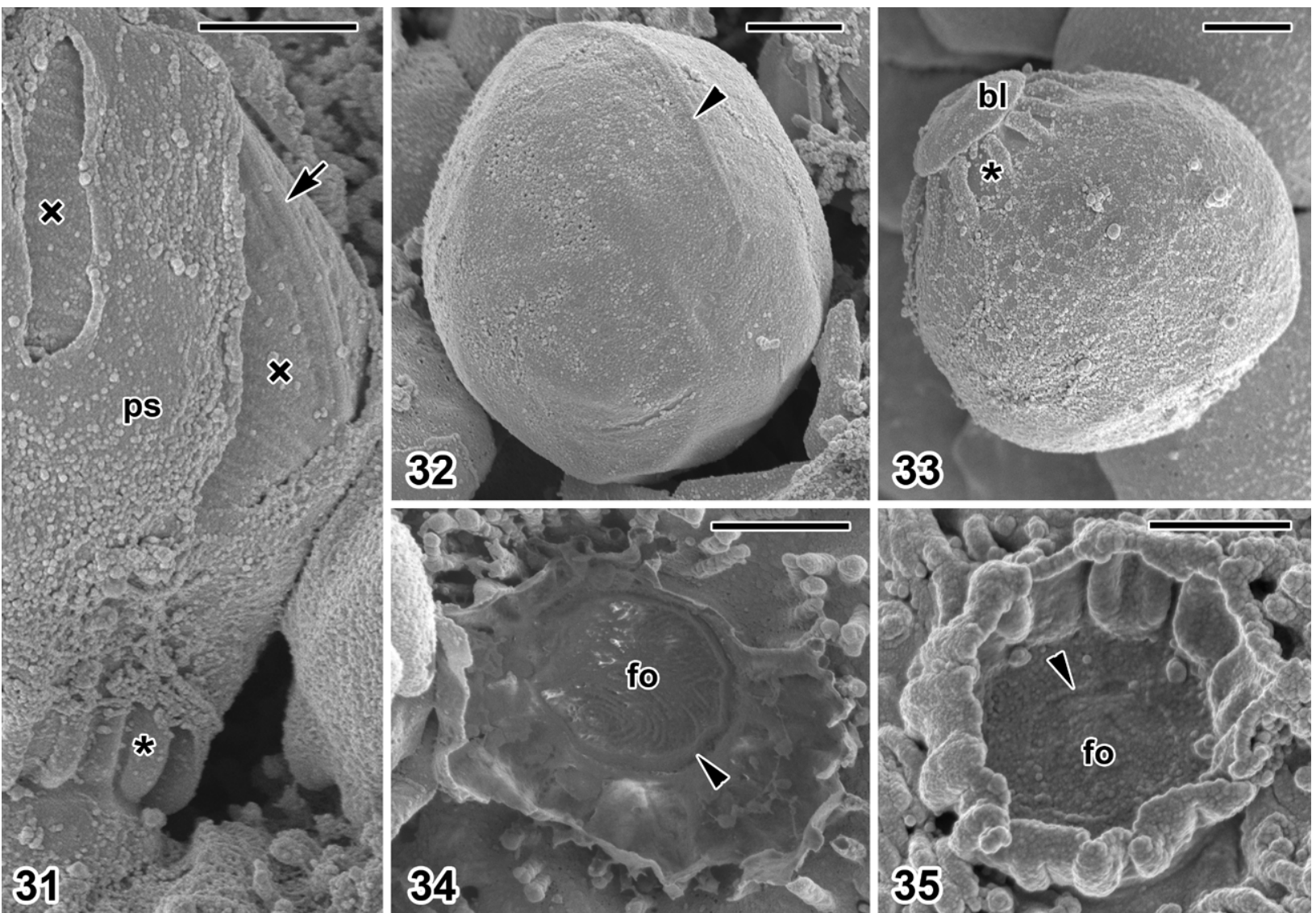

Figs. 31-35. Scanning electron micrographs of Cryptosporidium fragile sp. n. Fig. 31. Oocyst enveloped by ruptured parasitophorous sac; oocyst wall suture (arrow). Note the oocyst wall surface ornamentation $(\times)$. Fig. 32. Oocyst enveloped by parasitophorous sac showing protruding oocyst wall suture (arrowhead). Fig. 33. Detached parasitophorous sac containing unidentified developmental stage showing the button-like dense band area and radial folds of parasitophorous sac. Fig. 34. Base of recently ruptured parasitophorous sac with well preserved lamellae of the feeder organelle; Y-shaped membrane junction (arrowhead). Fig. 35. Base of ruptured parasitophorous sac revealing signs of microvillar surface regeneration as reflected by barely discernible feeder organelle and Y-shaped membrane junction (arrowhead) remnants. Abbreviations: bl - button-like dense band area; fo - feeder organelle; ps - parasitophorous sac; ${ }^{*}$ - radial folds of parasitophorous sac. All scale bars $=1 \mu \mathrm{m}$.

via a museum or other academic institution. The abovementioned criteria were followed in the description of C. fragile and an effort has been made to fulfil all these requirements.

\section{Cryptosporidium fragile: species parasitizing amphibian stomach}

Oocyst morphology, shape and size in particular, are traits differentiating the intestinal and stomach species, as originally pointed out by Tyzzer (1912). The oocysts of intestinal species are rounded, measuring 4-6 $\mu \mathrm{m}$ in diameter, while those of gastric species are larger and elliptical, reaching 7-9 $\mu \mathrm{m}$. The subspherical to elliptical shape of $C$. fragile already indicates its affinity with the gastric species. The oocysts of $C$. fragile are smaller compared with $C$. muris, C. andersoni or C. galli, but comparable in size with $C$. serpentis (Table 2). The shape variability and the irregular shape of the oocysts (Figs. 2, 3, 6) represent other traits not recorded previously in Cryptosporidium spp. The surface ornamenta- tion of the oocyst wall of C. fragile (Fig. 31) differs from smooth to finely wrinkled oocyst wall of $C$. parvum (Reduker et al. 1985) and smooth oocyst wall of $C$. muris (Valigurová et al. 2008). The fragility of the oocysts is a noteworthy character not even reported for the fish species (Alvarez-Pellitero and Sitjà-Bobadilla 2002).

The gastric cells parasitized by $C$. fragile occasionally formed what we call in this study the stem-like structures (Figs. 27, 28). This feature was previously observed in ileum of guinea pig infected with $C$. wrairi (Vetterling et al. 1971), suggesting that it might be common but overlooked in other cryptosporidia. The bell-shaped early trophozoites of $C$. fragile observed in our SEM preparations (Fig. 24) are comparable with those observed in TEM micrographs in cryptosporidia from fish and reptiles (Ostrovska and Paperna 1990, Paperna and Vilenkin 1996). The dense band below the feeder organelle in $C$. fragile was thick and less clearly 

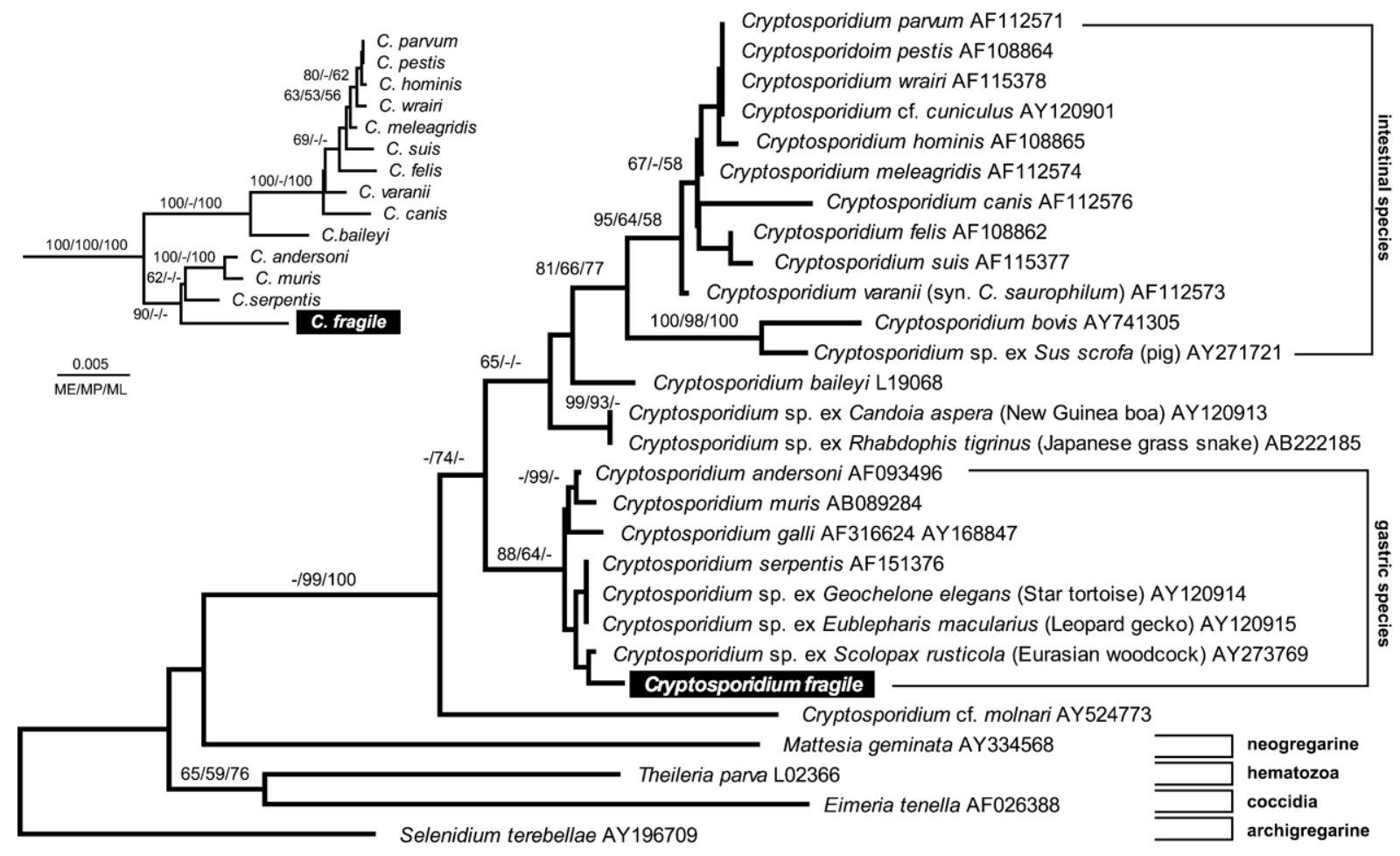

$\frac{0.01}{\text { ME/MP/ML }}$

Fig. 36. Phylogenetic reconstruction of Cryptosporidium species for the SSU rDNA. Reconstruction using available sequences from named Cryptosporidium species and selected genotypes with partial coverage and dataset of complete SSU rDNA sequences only (inset). The phylogenetic tree was inferred using the Minimum Evolution method. The bootstrap support values $(>50 \%)$ for Minimum Evolution (1,000 replicates) / Maximum Parsimony (500 replicates) / Maximum Likelihood (100 replicates) are shown next to the branches. The evolutionary distances were computed using the Maximum Composite Likelihood method. Minimum Evolution and Maximum Parsimony were calculated in MEGA4. Maximum Likelihood was calculated in PhyML 2.4.4 using GTR+G+I model.

differentiated into distinct layers compared to majority of the other cryptosporidian species; however, higher magnification revealed several layers, of which one was more distinct and finely indented as reported previously in C. muris and C. wrairi (Vetterling et al. 1971, Uni et al. 1987, Valigurová et al. 2007). Parasitophorous sac of C. fragile invariably possesses distinct, structurally uniform, radial folds evenly distributed around its base. The absence of these folds or their structural and spatial irregularity together with the presence of distinct and bulky filamentous projection in C. muris (weakly developed in C. fragile), make these two species clearly distinguishable from each other at the ultrastructural level (Valigurová et al. 2008).

Despite mentioned differences, the ultrastructure of C. fragile developmental stages was comparable to other cryptosporidian species. Unfortunately, many of the observed characters are insufficiently characterized in other Cryptosporidium spp., hampering the significance in species identification. Nevertheless, we find morphological traits correlating with individual host groups. Evident similarities occur within Cryptosporidium species from (i) fish, (ii) mammals and (iii) reptiles.
In the fish-affecting species, the surface of parasitophorous sac is covered by so-called rudimentary microvilli (Paperna and Vilenkin 1996). These structures, together with the localisation of the oocysts deep within the gastric mucosa, were used to erect the genus Piscicryptosporidium for the fish species (Paperna and Vilenkin 1996), which is currently considered a synonym of Cryptosporidium (Alvarez-Pellitero and Sitjà-Bobadilla 2002, Alvarez-Pellitero et al. 2004). We did not detect these structures in the amphibian gastric mucosa affected by $C$. fragile. In general, fish cryptosporidia exhibit well developed massive lamellae of the feeder organelle and inconspicuous filamentous projection ( $\mathrm{Pa}-$ perna and Vilenkin 1996, Alvarez-Pellitero and SitjàBobadilla 2002, Alvarez-Pellitero et al. 2004). Similarly, C. muris and C. andersoni, gastric species from mammalian hosts, seemingly exhibit common features, i.e. the shape and bulkiness of the filamentous projection (Uni et al. 1987, Masuno et al. 2006, Valigurová et al. 2007). On the other hand, the button-shaped feeder organelle with fine lamellae is present in C. fragile and both gastric as well as intestinal species from reptiles (Brownstein et al. 1977, Koudela and Modrý 1998). The 
Table 2. Summary of biological and morphological characteristics of named gastric Cryptosporidium species (C. baileyi and C. hominis are included for comparative purposes).

\begin{tabular}{|c|c|c|c|c|}
\hline Name & Oocysts size $(\mu \mathrm{m})$ & Localisation in the host & Type host / host range & Reference \\
\hline C. fragile sp. $\mathrm{n}$. & $6.2(5.5-7.0) \times 5.5(5.0-6.5)$ & Stomach & Toad $/ *$ & This study \\
\hline C. muris & $8.4(7.5-9.8) \times 6.3(5.5-7.0)$ & Stomach & Mouse / rodents & Lindsay et al. 2000 \\
\hline C. andersoni & $7.4(6.0-8.1) \times 5.5(5.0-6.5)$ & Stomach & Cattle /* & Lindsay et al. 2000 \\
\hline C. serpentis & $\begin{array}{l}6.2(5.6-6.6) \times 5.3(4.8-5.6) \\
6.6(5.9-6.7) \times 5.8(4.9-6.1)\end{array}$ & Stomach & Corn snake / reptiles & $\begin{array}{l}\text { Upton et al. } 1989, \\
\text { Graczyk et al. } 1998\end{array}$ \\
\hline C. galli & $8.25(8.0-8.5) \times 6.3(6.2-6.4)$ & Stomach & Chicken / birds & Ryan et al. 2003a \\
\hline C. molnari & $4.72(3.23-5.45) \times 4.47(3.02-5.04)$ & Stomach $^{\dagger}$ & Sea bream / sea fish & $\begin{array}{l}\text { Alvarez-Pellitero and } \\
\text { Sitjà-Bobadilla } 2002\end{array}$ \\
\hline C. baileyi & $6.2(6.3-5.6) \times 4.6(4.8-4.5)$ & Bursa Fabricii and cloaca & Chicken / birds & Current et al. 1986 \\
\hline C. hominis & $5.2(4.4-5.9) \times 4.86(4.4-5.4)$ & Intestine & Human $/ *$ & Morgan-Ryan et al. 2002 \\
\hline
\end{tabular}

${ }^{\dagger}$ Cryptosporidium molnari is rarely found also in intestine; *the species is either host specific or there is no comprehensive information available; oocyst sizes are derived from the referenced publications.

lamellae in these cryptosporidia seem to be fragile and often become disrupted during the specimen processing. Obviously, the morphology of both feeder organelle and the whole attachment site differ considerably between cryptosporidia found in different hosts and might be of some taxonomic significance.

Amphibians are rarely reported to be parasitized with Cryptosporidium spp. (Wright and Whitaker 2001, Cranfield and Graczyk 2006). Correspondingly, amphibians were refractory to experimental infection with characterized Cryptosporidium species (Graczyk et al. 1996, 1998). The zoonotic AUCP-1 strain of C. parvum 'bovine genotype', now recognized as $C$. pestis (Šlapeta 2006), was experimentally inoculated into African clawed frogs (Xenopus laevis) and poison-dart frogs (Dendrobates auratus), but experimental animals remained negative (Graczyk et al. 1996). Similarly, the inoculation of adult African clawed frogs (X. laevis) and tadpoles and adults of wood frogs (Rana sylvatica) by C. serpentis did not result in infections (Graczyk et al. 1998). In our cross-transmission experiments, we selected such hosts as to rule out the conspecificity of the studied isolate with some of the already described Cryptosporidium spp. Negative results of experiments support our conclusion that $C$. fragile is a separate species. Although the SCID mice are known to be a suitable model for intestinal and gastric cryptosporidiosis (Mead et al. 1991, Lindsay et al. 2000), they remained negative after inoculation with $C$. fragile indicating its inability to affect mammalian hosts. We further evaluated the host specificity of $C$. fragile in an array of frogs and tadpoles. None of the inoculated amphibians was found to be a susceptible host. Because we could not rule out the latent cryptosporidiosis in available Cryptosporidium-negative black-spined toads, we did not attempt to inoculate them as a positive control. However, the inoculum was freshly prepared and presence of high numbers of morphologically intact oocysts was confirmed before each trial. Although experiment using an outbred or wild animal is biased by the immunological status of the host, our findings suggest $C$. fragile to be host specific.
Phylogenetic analysis based on SSU rDNA has supported the fact that $C$. fragile falls in the monophyletic clade comprising the gastric species, using ME and MP phylogenetic methods. ML did not support the monophyly of gastric SSU rDNA sequences lining them up at the base of the intestinal species due to a poor reliability of the alignment of SSU rDNA, as previously discussed by Morrison (2006). Unfortunately, only partial SSU rDNA are available for novel genotypes as well as $C$. galli (Ryan et al. 2003a, b, 2004, Xiao et al. 2004b). The partial nature of these sequences rendered the position of $C$. fragile inaccurate within the gastric species and genotypes. Nonetheless, the sequence of $C$. fragile is distinct from any of the sequences available in databases, supporting the description of the new species.

\section{Amphibian cryptosporidiosis: fact or fiction}

Occurrence of Cryptosporidium oocysts in the faeces of a captive mice-fed ornate horned frog, Ceratophrys ornata (Crawshaw and Mehren 1987) is probably the first report related to amphibians. Another two reports deal with natural and experimental cryptosporidiosis in giant toads, Rhinella marina (previously Bufo marinus) (Arcay and Bruzal 1993, Arcay et al. 1995). While these reports provide noteworthy data about cryptosporidiosis in $R$. marina, the identity of Cryptosporidium isolate used in the experiments is unclear and the cryptosporidiosis in $R$. marina thus needs further investigation and re-evaluation.

The only well described cryptosporidiosis in frogs is a case of proliferative gastritis in a single laboratoryreared African clawed frog (X. laevis) associated with finding of Cryptosporidium sp. in the gastric mucosa (Green et al. 2003). The authors have demonstrated developmental stages using histological techniques as well as TEM; moreover the oocysts were recovered from the sediment in the aquarium. The affected frog had been laboratory-reared by a commercial producer and kept in a laboratory facility in the USA with $\sim 2,000$ individuals, but no other frog in the facility was affected. The identity of this Cryptosporidium sp. remains elusive, but it is unlikely that it was any of the known species. Cryptosporidia are considered to be host specific within either 
fish, reptiles, birds or mammals. The only exception is C. meleagridis infecting both mammals and birds (Akiyoshi et al. 2003). Conspecificity of $X$. laevis-isolate with $C$. fragile is unlikely because the morphological characteristics well differentiate these two cryptosporidia. The button-shaped feeder organelle is apparently more compact with an obvious Y-shaped membrane junction and the dense band is more distinct in $C$. fragile [compare our Figs. 14, 19 with fig. 2A in Green at al. (2003)]. Moreover, neither the fragility nor the irregular shape of $C$. fragile oocysts was noticed by Green at al. (2003).

The prevalence of $C$. fragile in toads in Malaysia remains unknown. Similarly, we do not know whether Duttaphrynus melanostictus is the true natural host or an accidental host that acquired the infection in the exporter facilities. Generally, quarantine measures during the importation/exportation of live exotic amphibians and fish are weak or nil and need careful revision. Strict implementation of quarantine and further regulations are necessary. Our experience with $C$. fragile imported from Malaysia suggests that quarantine measures for live amphibians are insufficient both in the exporting as well as the importing country. We recommend the examination of imported amphibians for the presence of Cryptosporidium spp. as an obligatory part of implemented measures.

Further research is needed to elucidate the conditions under which an amphibian becomes a susceptible host and the extent of cryptosporidiosis in amphibians. Such information are of special significance in the context of the global amphibian declines, frequently associated with emerging infectious diseases that cause mass dieoffs and extinctions of naïve amphibian populations (Daszak et al. 2003, Stuart et al. 2004, Skerratt et al. 2007).

\section{Taxonomic summary}

\section{Cryptosporidium fragile sp. $\mathrm{n}$.}

T y p e h o s t: Black-spined toad Duttaphrynus melanostictus (Schneider, 1799) (Anura: Bufonidae).

T y p e 1 o c a 1 i t y : Malay Peninsula; exact locality unknown.

Site of infection: Gastric mucosal cells.

Pr e vale n c e : $22 \%(4 / 18)$ and $83 \%(15 / 18)$ D. melanostictus infected at the time of import and within 90 days of the study, respectively.

Ty pe material/hapantoty pe: Histological sections of infected stomach, gold-coated infected stomach tissue, infected stomach in absolute ethanol, digital photo- micrographs on $\mathrm{CD}$, and symbiotype $D$. melanostictus specimen with liver tissue sample in absolute ethanol - deposited at the type parasitological collection of the Institute of Parasitology, Biology Centre, Academy of Sciences of the Czech Republic, České Budějovice, No. IP ASCR Prot. Coll.: P-3.

D N A s e qu e n c e s: SSU rDNA submitted to GenBank ${ }^{\mathrm{TM}}$ under the accession numbers EU162751-EU162754.

E t y m o 1 o g y : The specific epithet "fragile" (Latin, adj., meaning fragile, easily broken) refers to the extraordinary sensitivity of oocysts to hypertonic conditions and early disintegration of oocysts in water.

Remarks. Up to date there are seven Cryptosporidium spp. described to parasitize primarily stomachs of vertebrates; $C$. muris and $C$. andersoni in mammals, $C$. serpentis in reptiles, C. galli in birds, and C. cichlidis, C. reichenbachklinkei and C. molnari in fish. Cryptosporidium fragile is the first species described from an amphibian host. Oocyst size of $C$. fragile is similar to $C$. serpentis, but its oocysts differ in marked shape variability and irregularity. In addition, we could not experimentally infect the corn snake (Pantherophis guttatus) with $C$. fragile. Oocysts of cryptosporidia from fish are smaller, while mammalian and avian cryptosporidia are larger. Ultrastructurally, oocysts of $C$. fragile possess a surface ornamentation not recorded in other Cryptosporidium spp. Cryptosporidium fragile differs from all ultrastructurally characterized species in the weakly developed filamentous projection coupled with the extremely fine lamellae of the button-shaped feeder organelle and the thick dense band. Furthermore, the structurally uniform radial folds evenly distributed around the base of parasitophorous sac, which are inserted under the button-like area of the dense band, differentiate $C$. fragile from other Cryptosporidium spp. possessing irregular folds or lacking these folds.

Acknowledgements. This study was supported by grants of the Grant Agency of the Czech Republic Nos. 524/03/H133 and 524/05/0992, Institute of Parasitology (projects Z602 20518 and LC 522), and by a grant MSM 0021622416. Authors are greatly indebted to the members of the Laboratory of Electron Microscopy (Institute of Parasitology), Věra Kučerová, Blanka Cikánová and Martina Tesařová for generous help and technical assistance. JS would like to acknowledge support from the Faculty of Veterinary Science, University of Sydney, towards the preparation of this manuscript. We also thank Jakub Bednár for provision of amphibians involved in this study. Fig. 31 was taken, with permission of the Australian Society for Parasitology, from Fig. 6A in Valigurová et al. (doi:10.1016/j.ijpara.2007.11.003), International Journal for Parasitology, published by Elsevier.

\section{REFERENCES}

AKiyoshi D.E., Dilo J., PEARson C., ChapMan S., Tumwine J., TZIPORI S. 2003: Characterization of Cryptosporidium meleagridis of human origin passaged through different host species. Infect. Immun. 71: 1828-1832.

Alvarez-Pellitero P., Quiroga M.I., Sitjà-Bobadilla A., Redondo M.J., PAlenzuela O., PAdrós F., VÁzQuez S.
NiETO J.M. 2004: Cryptosporidium scophthalmi n. sp. (Apicomplexa: Cryptosporidiidae) from cultured turbot Scophthalmus maximus. Light and electron microscope description and histopathological study. Dis. Aquat. Org. 62: 133-145.

AlvareZ-Pellitero P., SitjÀ-BOBADIlla A. 2002: Cryptosporidium molnari n. sp. (Apicomplexa: Cryptosporidiidae) 
infecting two marine fish species, Sparus aurata L. and Dicentrarchus labrax L. Int. J. Parasitol. 32: 1007-1021.

ARCAY L., BAEZ DE Bordes E., BRUZAL E. 1995: Criptosporidiosis experimental en la escala de vertebrados. I. - Infection experimentales II. - Estudio histopatológico. Parasitol. al Día 19: 20-29.

ARCAY L., BRUZAL E. 1993: Cryptosporidium en ríos de Venezuela. Encuesta epidemiológica de una población humana y fauna en convivencia. Parasitol. al Día 17: 11-18.

BrownStein D.G., STRANDBERG J.D., MONTALI R.J., BUSH M., FORTNER J. 1977: Cryptosporidium in snakes with hypertrophic gastritis. Vet. Pathol. 14: 606-617.

Chen X.M., Keithly J.S., Paya C.V., Larusso N.F. 2002: Cryptosporidiosis. N. Engl. J. Med. 346: 1723-1731.

CRANFIEld M.R., GRACZYK T.K. 2006: Cryptosporidiosis. In: D.R. Mader (Ed.), Reptile Medicine and Surgery. Second Edition. Saunders Elsevier, St. Louis, pp. 756-762.

Crawshaw G.J., Mehren K.G. 1987: Cryptosporidiosis in ZOO and wild animals. In: Erkrankungen der Zootiere. Verhandlungsbericht des 29. Internationalen Symposiums über die Erkrankungen der Zootiere, Cardiff. Akademie-Verlag, Berlin, pp. 353-362.

CURRENT W.L., UPTON S.J., HAYNES T.B. 1986: The life cycle of Cryptosporidium baileyi n. sp. (Apicomplexa, Cryptosporidiidae) infecting chickens. J. Protozool. 33: 289-296.

DaszaK P., CunNingham A.A., HYATT A.D. 2003: Infectious disease and amphibian population declines. Divers. Distrib. 9: 141-150.

EGYED Z., SRÉTER T., SZÉLL Z., VARGA I. 2003: Characterization of Cryptosporidium spp. - recent developments and future needs. Vet. Parasitol. 111: 103-114.

FAYER R., MORGan U., UPTON S.J. 2000: Epidemiology of Cryptosporidium: transmission, detection and identification. Int. J. Parasitol. 30: 1305-1322.

GRACZYK T.K., CRANField M.R., GeITNER M.E. 1998: Multiple Cryptosporidium serpentis oocyst isolates from captive snakes are not transmissible to amphibians. J. Parasitol. 84: $1298-1300$.

GRACZYK T.K., FAYER R., CRANFIELD M.R. 1996: Cryptosporidium parvum is not transmissible to fish, amphibians, or reptiles. J. Parasitol. 82: 748-751.

Green S.L., Bouley D.M., Josling C.A., FAYeR R. 2003: Cryptosporidiosis associated with emaciation and proliferative gastritis in a laboratory-reared South African clawed frog (Xenopus laevis). Comp. Med. 53: 81-84.

GUINDON S., GASCUEL O. 2003: A simple, fast, and accurate algorithm to estimate large phylogenies by maximum likelihood. Syst. Biol. 52: 696-704.

Koudela B., MODRÝ D. 1998: New species of Cryptosporidium (Apicomplexa, Cryptosporidiidae) from lizards. Folia Parasitol. 45: 93-100.

LindSAY D.S., UPTON S.J., OWENS D.S., MoRgan U.M., MEAD J.R., BLAGBURN B.L. 2000: Cryptosporidium andersoni n. sp. (Apicomplexa: Cryptosporiidae) from cattle, Bos taurus. J. Eukaryot. Microbiol. 47: 91-95.

Masuno K., Yanai T., Hirata A., Yonemaru K., SAKai H., SATOH M., MASEGI T., NAKAI Y. 2006: Morphological and immunohistochemical features of Cryptosporidium andersoni in cattle. Vet. Pathol. 43: 202-207.

Mead J.R., Arrowood M.J., Sidwell R.W., Healey M.C. 1991: Chronic Cryptosporidium parvum infections in congenitally immunodeficient SCID and nude mice. J. Infect. Dis. 163: 1297-1304.

Morgan-Ryan U.M., FAll A., WARD L.A., HiJjawi N., SULAIMAN I., FAYER R., THOMPSON R.C.A., OLSON M., LAL A., XIAO L. 2002: Cryptosporidium hominis n. sp. (Apicomplexa:
Cryptosporidiidae) from Homo sapiens. J. Eukaryot. Microbiol. 49: 433-440.

MORRISON D.A. 2006: Phylogenetic analyses of parasites in the new millennium. Adv. Parasitol. 63: 1-124.

OSTROVSKA K., PAPERNA I. 1990: Cryptosporidium sp. of the starred lizard Agama stellio: ultrastructure and life cycle. Parasitol. Res. 76: 712-720.

PAPERNA I., VILENKIN M. 1996: Cryptosporidiosis in the gourami Trichogaster leeri: description of a new species and a proposal for a new genus, Piscicryptosporidium, for species infecting fish. Dis. Aquat. Org. 27: 95-101.

PosAdA D., CRANDALl K.A. 1998: MODELTEST: testing the model of DNA substitution. Bioinformatics 14: 817-818.

REDUKER D.W., SPEER C.A., BLIXT J.A. 1985: Ultrastructure of Cryptosporidium parvum oocysts and excysting sporozoites as revealed by high resolution scanning electron microscopy. J. Protozool. 32: 708-711.

RYAN U., O'HARA A., XIAO L. 2004: Molecular and biological characterization of a Cryptosporidium molnari-like isolate from a guppy (Poecilia reticulata). Appl. Environ. Microbiol. 70: 3761-3765.

RYAN U.M., XiaO L., READ C., Sulaiman I.M., Monis P., LAL A.A., FAYer R., PAVLÁSEK I. 2003a: A redescription of Cryptosporidium galli Pavlásek, 1999 (Apicomplexa: Cryptosporidiidae) from birds. J. Parasitol. 89: 809-813.

Ryan U., XiaO L., Read C., Zhou L., Lal A.A., PaVlásek I. 2003b: Identification of novel Cryptosporidium genotypes from the Czech Republic. Appl. Environ. Microbiol. 69: 4302-4307.

Skerratt L.F., Berger L., Speare R., CASHINS S., MCDONALD K.R., PHillotT A.D., Hines H.B., KenYON N. 2007: Spread of chytridiomycosis has caused the rapid global decline and extinction of frogs. Ecohealth 4: 125-134.

ŠLAPETA J. 2006: Cryptosporidium species found in cattle: a proposal for a new species. Trends Parasitol. 22: 469-474.

ŚLAPETA J. 2008: Centenary of the genus Cryptosporidium: from morphological to molecular species identification. In: M.G. Ortega-Pierres, S. Caccio, R. Fayer, T. Mank, H. Smith and R.C.A. Thompson (Eds.), Giardia and Cryptosporidium. CABI Publishing, Morelia, Mexico. (In press.)

SPano F., PUtignani L., MClauChlin J., CASEMORE D.P., CRiSANTI A. 1997: PCR-RFLP analysis of the Cryptosporidium oocyst wall protein (COWP) gene discriminates between $C$. wrairi and C. parvum, and between C. parvum isolates of human and animal origin. FEMS Microbiol. Lett. 150: 209217.

StUART S.N., ChanSON J.S., COX N.A., YOUNG B.E., RODRIGUES A.S.L., Fischman D.L., WALLER R.W. 2004: Status and trends of amphibian declines and extinctions worldwide. Science 306: 1783-1786.

SUlAiMAN I.M., LAL A.A., XIAO L. 2002: Molecular phylogeny and evolutionary relationships of Cryptosporidium parasites at the actin locus. J. Parasitol. 88: 388-394.

TAMURA K., DudLEY J., NeI M., Kumar S. 2007: MEGA4: Molecular Evolutionary Genetics Analysis (MEGA) Software Version 4.0. Mol. Biol. Evol. 24: 1596-1599.

THOMPSON R.C.A., OLSON M.E., ZHU G., ENOMOTO S., ABRAHAMSEN M.S., HIJJAWI N.S. 2005: Cryptosporidium and cryptosporidiosis. Adv. Parasitol. 59: 77-158.

TILlEY M., UPTON S.J., FreED P.S. 1990: A comparative study of the biology of Cryptosporidium serpentis and Cryptosporidium parvum (Apicomplexa: Cryptosporidiidae). J. Zoo Wildl. Med. 21: 463-467.

TYZZER E.E. 1907: A sporozoan found in the peptic glands of the common mouse. Proc. Soc. Exp. Biol. Med. 5: 12-13. 
TYZZER E.E. 1912: Cryptosporidium parvum (sp. nov.), a coccidium found in the small intestine of the common mouse. Arch. Protistenkd. 26: 394-412.

UNi S., ISEKI M., MAEKAWA T., MORIYA K., TAKADA S. 1987 Ultrastructure of Cryptosporidium muris (strain RN 66) parasitizing the murine stomach. Parasitol. Res. 74: 123-132.

Upton S.J., MCALlister C.T., FrEED P.S., BARNARD S.M. 1989: Cryptosporidium spp. in wild and captive reptiles. J. Wildl. Dis. 25: $20-30$

VAligurová A., HofmanNová L., Koudela B., VÁvra J. 2007: An ultrastructural comparison of the attachment sites between Gregarina steini and Cryptosporidium muris. J. Eukaryot. Microbiol. 54: 495-510.

VAligurová A., JiRKU゚ M., KOUdela B., Gelnar M., MOdRÝ D., ŠLAPETA J. 2008: Cryptosporidia: epicellular parasites embraced by the host cell membrane. Int. J. Parasitol. (In press.)

VETTERLING J.M., TAKEUCHI A., MADDEN P.A. 1971: Ultrastructure of Cryptosporidium wrairi from the guinea pig. J. Protozool. 18: 248-260.

WRIGHT M.K., WHITAKER B.R. 2001: Quarantine. In: M.K. Wright and B.R. Whitaker (Eds.), Amphibian Medicine and

Received 2 November 2007
Captive Husbandry. Krier Publishing Company, Malabar, Florida, pp. 303-307.

Xiao L., Escalante L., Yang C., Sulaiman I., Escalante A.A., MONTALi R.J., FAYer R., LAL A.A. 1999: Phylogenetic analysis of Cryptosporidium parasites based on the smallsubunit rRNA gene locus. Appl. Environ. Microbiol. 65: 1578-1583.

XIAO L., FAYER R., RYAN U., UptON S.J. 2004a: Cryptosporidium taxonomy: recent advances and implications for public health. Clin. Microbiol. Rev. 17: 72-97.

XiaO L., Limor J., MORGan U.M., Sulaiman I.M., ThOMPSON R.C.A., LAL A.A. 2000: Sequence differences in the diagnostic target region of the oocyst wall protein gene of Cryptosporidium parasites. Appl. Environ. Microbiol. 66: 54995502.

XiAO L., RYAN U.M., GRACZYK T.K., LIMOR J., LI L., KOMBERT M., Junge R., Sulaiman I.M., Zhou L., ARROWOOd M.J., KOUDELA B., MODRÝ D., LAL A.A. 2004b: Genetic diversity of Cryptosporidium spp. in captive reptiles. Appl. Environ. Microbiol. 70: 891-899.

Accepted 14 January 2008 